\title{
First-Time Mothers' Experiences of a Planned Cesarean Birth
}

\author{
Denise Puia, PhD, RNC
}

\begin{abstract}
Even though a cesarean birth is planned, women may experience physical and psychological difficulties. This qualitative study explored the overall experience of first-time mothers having a planned cesarean birth, which was any cesarean in which the decision was made prior to the onset of labor or labor induction. Eleven primipara postpartum mothers shared their stories. Data were analyzed using Riessman's method of thematic narrative analysis. Seven overarching themes revealed a need to accept a cesarean birth and create realistic expectations. Education and support specific to planned cesarean births need to be provided to the woman and her support person both before and after the birth. Realistic expectations will improve the adaptation process.
\end{abstract}

The Journal of Perinatal Education, 27(1), http://dx.doi.org/10.1891/1058-1243.27.1.50

Keywords: planned cesarean birth, primipara, narrative analysis, Roy's Adaptation Model

Cesarean births are the most common major operating room procedure performed in the United States (Weiss, Elixhauser, \& Andrews, 2014). Almost one mother in every three gives birth by cesarean (Hamilton, Martin, Osterman, Curtin, \& Mathews, 2015). More than one third of these cesareans are to women having their first child (Zhang et al., 2010). It is crucial that health-care providers understand not only the influences that led first-time mothers to have a planned cesarean birth but also the physical and psychological outcomes since more than half of these women will choose to have repeat cesarean births with subsequent pregnancies (Guise et al., 2010).

Childbirth is a pivotal point in a woman's life that is shaped by the outcome as well as by her perception of the event. Karlström, Nystedt, and Hildingsson (2011) found women who had a planned cesarean birth were not pleased with the decision-making process or the antenatal care and reported a more negative birth experience than the women who had a planned vaginal birth. In contrast, positive experiences were reported in the presence of strong nursing support (Bryanton, Gagnon, Johnston, \& Hatem, 2008). It is especially important to examine the impact of the birthing experience on first-time mothers since they have no prior experience with which to compare the event (Dahlen, Barclay, \& Homer, 2010). Furthermore, first-time mothers' experiences can impact future childbirth decisions (Stadlmayr et al., 2006). 


\section{LITERATURE REVIEW}

The present body of research has mostly studied specific aspects, either physical or psychological, of a cesarean birth. Only a few studies have explored the overall cesarean birth experience, from the time of the decision through the postpartum recovery and including both the physical and emotional aspects of the birth (Blüml et al., 2012; Fenwick, Staff, Gamble, Creedy, \& Bayes, 2010; Fries, 2010; Puia, 2013b; Redshaw \& Hockley, 2010) and no studies have specifically examined first-time mothers' overall experiences related to a planned cesarean birth. In a quantitative study, Blüml et al. (2012) assessed 48 women, both primiparas and multiparas, who had a planned cesarean birth. The results indicated that only half the women felt adequately informed about the cesarean procedure and majority (83.3\%) of the women felt anxious during the surgery (Blüml et al., 2012).

Two qualitative studies revealed similar descriptions associated with a cesarean birth (Fries, 2010; Puia, 2013b). Fries (2010) conducted a phenomenological study of the overall experience of seven African American women, both primiparas and multiparas, who had an unplanned cesarean birth. Fries (2010) defined an unplanned cesarean as any cesarean in which the woman learned of the surgery less than 2 hours before the surgery. Analysis of the interviews resulted in five themes which conveyed an overall experience of sadness and disappointment (Fries, 2010). A metasynthesis (Puia, 2013b) investigated the experience of women having a cesarean birth by examining the 10 qualitative studies that had been conducted. Analysis of the data resulted in six overarching themes: that conveyed notions of fear, failure, difficulty bonding, lack of control, and mistrust. Ten themes depicting a negative experience also emerged from a descriptive qualitative survey of 2960 English women conducted by Redshaw and Hockley (2010).

A review of the literature revealed the majority of studies examined women's experiences that have included both primiparas and multiparas who had vaginal birth as well as planned and unplanned cesarean births all within the same study, thus making it difficult to determine if the results are applicable specifically to primiparas undergoing planned cesarean births. The mixture of parity and birth method within single studies may have contributed to the many negative experiences reported. No studies have specifically examined the experience of first time mothers who had a planned cesarean birth.
It is crucial that healthcare providers understand not only the

influences that led first time mothers to have a planned cesarean

birth but also the physical and psychological outcomes.

The purpose of this narrative analysis was to explore the experience of first-time mothers having a planned cesarean birth. The specific research question was:

What is the overall experience of a planned cesarean birth (either for medical or social reasons) including the entire birthing process; beginning with the preceding factors that influenced first-time mothers to have a planned cesarean birth, including the physical and emotional experience of the birth itself, and concluding with the postpartum period and complete recovery?

\section{METHODS \\ Design}

Narrative analysis is a type of qualitative design in which the emphasis of the investigation is on the participants' stories. Riessman (1993) believed that because narratives are "meaning making structures" (p. 4) they must be kept intact and analyzed as a whole. A unique piece of Riessman's (2008) method is the use of a theoretical framework, in this case Roy's Adaptation Model (RAM) (Roy \& Andrews, 1999), with which to guide the inquiry. According to RAM (Roy \& Andrews, 1999), a person is an adaptive system that responds to environmental stimuli through regulator and cognator subsystems. The regulator subsystems are the neurological, chemi$\mathrm{cal}$, and hormonal response to stimuli and were not addressed in this study. How well a person adapts is evaluated through four modes. Figure 1 depicts the concepts and operational definitions of the model.

\section{Sample}

A purposive sample of postpartum women who underwent a planned cesarean birth was studied. Additional participants were also recruited through snowball sampling. A planned cesarean birth was operationally defined as a cesarean in which the decision was made prior to the onset of labor or labor induction. The decision may have been for medical reasons, the woman's fear, or physician recommendation, and in fact may not have been the woman's chosen method of birth. The inclusion criteria were 
Roy adaptation model

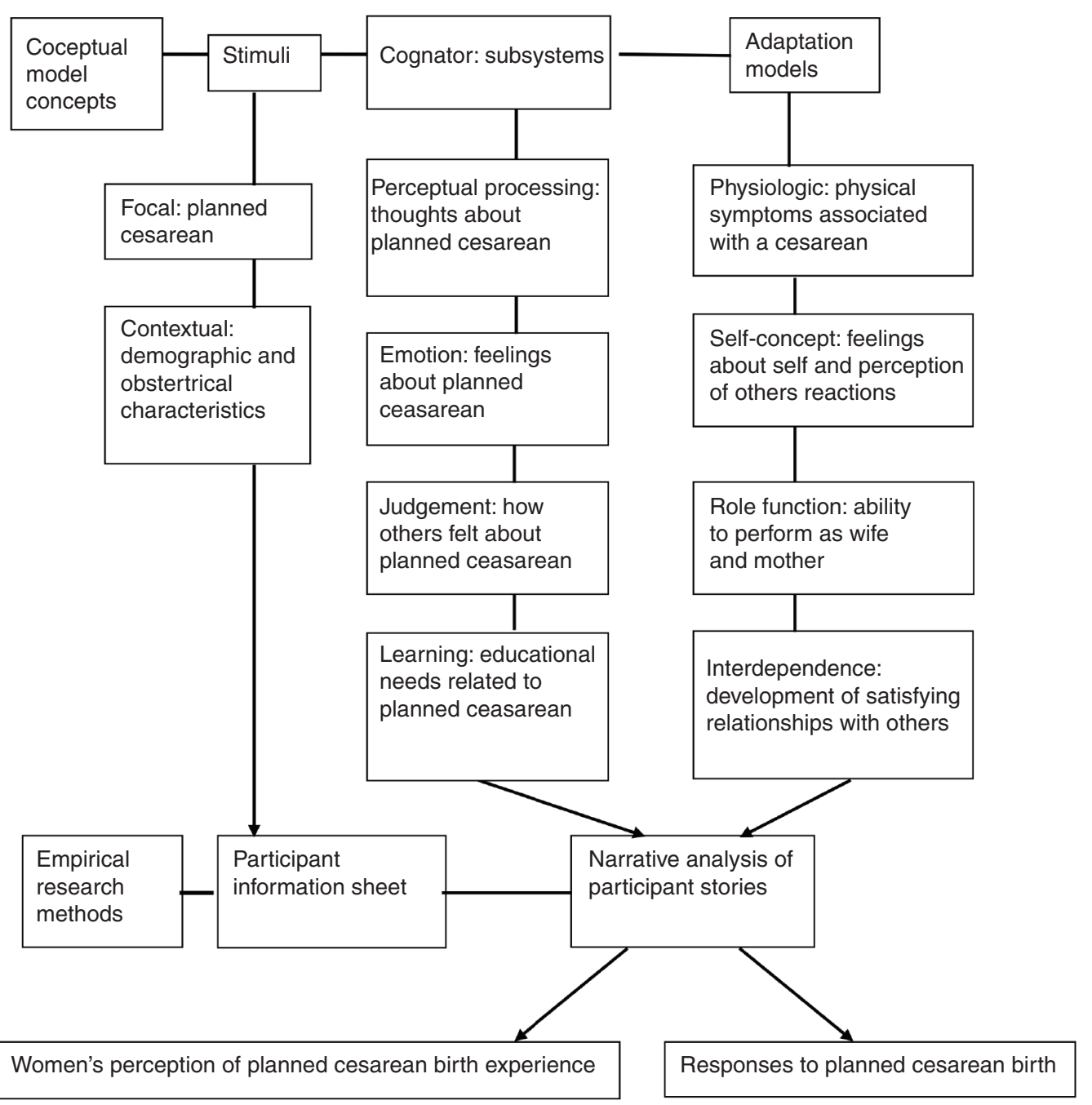

Figure 1. Conceptual-empirical structure for the study of perceptions and responses to a planned cesarean birth.

as follows: all participants must have had a birth of a live infant, must be able to read and write English and be a minimum of 18 years of age. Since research has shown that women can vividly recall giving birth even 15-20 years later (Simkin, 1992; Waldenstrom, 2003), there was no exclusion criteria regarding how long ago the mothers may have given birth.

\section{Data Collection Procedure}

Once approval was obtained from the university's institutional review board, women were recruited via a flyer from a local pediatrician's office and referrals from study participants. Interested women contacted the researcher by email upon which time further information was provided. Two options were available for participation: email or interview.
Those women who wished to participate by email were able to write their story at their convenience and send it upon completion. Consent was implied when the woman emailed her story to the researcher. For those women who wished to be interviewed, informed consent was obtained prior to the interview. The interviews were audio taped and transcribed by the researcher. All participants, regardless of the method of response, were asked to respond to the statement,

Please describe for me in as much detail as you remember the story of your planned cesarean birth experience beginning with when and how the decision was made for you to have a cesarean birth, the physical and emotional experience of the birth itself and 
continuing up until the time you felt fully recovered. Please share all of your thoughts, emotions, opinions, and any specific examples you wish to share.

In addition to their stories, all participants provided demographic information.

\section{Data Analysis}

Riessman's $(1993,2008)$ method of thematic narrative analysis was used to interpret each story as a whole. According to Riessman (1993), there are five levels of experience involved in narrative analysis: attending, telling, transcribing, analyzing, and reading. Attending involves the participant making an active decision to acknowledge certain aspects of a story as important. Telling is characterized by the participant's recount of the events and his or her interpretation of the experience. Transcribing occurs as the participant's story is recorded and then translated into written text. Analysis takes place as the researcher individually analyzes each narrative within a theoretical framework. The commonalities among stories are then transformed by the researcher into one overall depiction called the metastory. Reading, the final level of experience, occurs when the drafts of the metastory are shared with colleagues or the participants for review. Feedback may then be incorporated into the metastory.

\section{RESULTS}

\section{Sample}

A total of 11 women participated in the study. Seven of the narratives were obtained through in person interviews and the remaining four stories were shared via email. All of the cesarean births occurred on the East Coast of the United States in Connecticut, Massachusetts, New Jersey, or Pennsylvania. The participants were all white, married women with college degrees. The maternal, obstetrical, and interview characteristics are presented in Table 1.

\section{A Metastory of First-Time Mothers' Experiences of a Planned Cesarean Birth}

Table 2 details the themes and subthemes that embodies the experience of first-time mothers who have a planned cesarean birth.

\section{Theme 1: The Decision, Not Much of a Choice}

All the participants began their story with how they came to have a planned cesarean. Two of the participants planned to have a cesarean birth before they were even pregnant due to the anxiety they felt over birthing vaginally. The remaining nine women did not want to have a cesarean birth, but they felt they had no choice. Table 3 reports the reasons for the planned cesarean births according to the participants. Several women were encouraged by their physician to have a cesarean birth. One participant remembered, "He offered me the option of going home and being induced next week or having a cesarean that day, but he explained that he was not on call that weekend and if something happened he would not be the one to see me."

The notion that a cesarean birth was safer for the baby reinforced the participants' feelings of not having a choice. One participant explained, "I wanted

TABLE 1

Participant Demographics

\begin{tabular}{|c|c|c|c|c|c|c|c|c|}
\hline Participant & $\begin{array}{l}\text { Maternal } \\
\text { age }\end{array}$ & $\begin{array}{l}\text { Age at } \\
\text { decision }\end{array}$ & $\begin{array}{l}\text { Present age } \\
\text { of first child }\end{array}$ & $\begin{array}{l}\text { Weeks pregnant } \\
\text { at decision }\end{array}$ & $\begin{array}{l}\text { Weeks } \\
\text { pregnant } \\
\text { at birth }\end{array}$ & $\begin{array}{l}\text { State } \\
\text { where } \\
\text { birthed }\end{array}$ & $\begin{array}{l}\text { No. of } \\
\text { words }\end{array}$ & $\begin{array}{l}\text { No. of } \\
\text { interview } \\
\text { minutes }\end{array}$ \\
\hline 1 & 33 & 31 & 1 & 8 & 37 & CT & 1,268 & \\
\hline 2 & 37 & 30 & 6 & 16 & 35.6 & СT & 1,288 & \\
\hline 3 & 33 & 28 & 3 & $383 / 7$ & $391 / 7$ & PA & 1,137 & \\
\hline 4 & 46 & 41 & 4 & 0 & 38 & $\mathrm{CT}$ & 2,384 & 40:49:00 \\
\hline 5 & 33 & 26 & 6 & 0 & 39 & PA & 1,479 & $12: 41$ \\
\hline 6 & 33 & 33 & 4 weeks & 32 & $393 / 7$ & CT & 3,282 & $26: 53: 00$ \\
\hline 7 & 32 & 31 & 3 months & 38 & 38 & $\mathrm{NJ}$ & 1,238 & \\
\hline 8 & 32 & 31 & $51 / 2$ months & 39 & $402 / 7$ & $\mathrm{NJ}$ & 2,663 & $28: 56: 00$ \\
\hline 9 & 28 & 28 & 7 weeks & 0 & 39 & $\mathrm{CT}$ & 3,327 & 28:02:00 \\
\hline 10 & 43 & 37 & 5 & 0 & 36 & CT & 3,393 & 40:03:00 \\
\hline 11 & 50 & 23 & 27 & 0 & 39 & MA & 972 & $30: 51: 00$ \\
\hline
\end{tabular}


TABLE 2

Overarching Themes

\begin{tabular}{l} 
Overarching theme one: \\
The decision, not much of a choice \\
Subthemes for overarching theme one \\
1. Influence of birth stories \\
2. Safety of the baby \\
Overarching theme two: \\
Acceptance of birth method \\
Subthemes for overarching theme two \\
1. Healthy baby \\
2. Faith and support \\
Overarching theme three: \\
Emotional roller coaster of birth \\
Subthemes for overarching theme three \\
1. Fear \\
2. Doubt \\
3. Denial \\
4. Calm \\
5. Joy \\
6. Relief \\
Overarching theme four: \\
Physical recovery, feeling like myself \\
Subthemes for overarching theme four \\
1. Presence of support \\
2. Physically active/fit \\
3. Breastfeeding difficulties \\
Overarching theme five: \\
Emotional recovery, a kaleidoscope of feelings \\
Subthemes for overarching theme five \\
1. Presence of support \\
2. Breastfeeding difficulties \\
Overarching theme six: \\
Expectations, a picture in my mind \\
Subthemes for overarching theme six \\
1. Importance of prior information \\
2. Role of health-care providers \\
Overarching theme seven: \\
Outcomes, ties that bind \\
Subthemes for overarching theme seven \\
1. Improved relationships \\
2. Happy to be a mom \\
\hline
\end{tabular}

desperately to birth vaginally, but I opted for the planned cesarean, as in the end the risk to the baby was much less." These women were willing to forego their own desires for a vaginal birth in order to provide what they felt was the safer alternative for their baby.

Many of the participants turned to family and friends for information. What they heard were stories of short, easy cesarean births and long, horrible,

\section{The notion that a cesarean birth was safer for the baby reinforced}

\section{the participants' feelings of not having a choice. These women}

\section{were willing to forego their own desires for a vaginal birth in order}

to provide what they felt was the safer alternative for their baby.
TABLE 3

Reasons for Planned Cesarean as Perceived by the Participants

Requested by women

Always wanted cesarean due to anxiety of vaginal birth. In addition, increased anxiety related to fear of injury of prior joint replacement.

Always wanted cesarean due to anxiety of vaginal birth. In addition, increased anxiety related to chronic hypertension and fear of increased complications.

Required by physician

Twins, one with oligohydramnios

Prior uterine surgery

Multiple previous bowel resections

Two women were breech, did not want to attempt version

Recommended by physician

Vertex/vertex twins

Bicorneuate uterus

Estimated to be big baby

Pregnancy induced hypertension, doctor offered induction next week, or cesarean that day with him

painful labors. One woman shared, "My cousin had a horrible 23-hour natural birth. She gave me all the horrible details which made me even more certain that a c-section was the way to go." These negative depictions of vaginal births increased the participants' feelings about not having viable birthing options.

\section{Theme 2: Acceptance of Birth Method}

The nine women who envisioned vaginal births needed to come to terms with an alternative birthing method. Many times, feelings of acceptance would be impeded by people's comments. One participant explained, "People would ask me if I was still thinking about having a natural birth because it was good for a baby to go through the natural delivery process." Other times women were troubled by their own ideas of what is the ideal birth method. One participant shared, "I didn't want to have a cesarean birth. . . I didn't feel it was normal. I had a perception that they had to work harder and therefore deserved the prize more- the reality was I was just going to lay there." Other participants also struggled with feelings of grief over "not having that womanly experience."

Eventually, all the women came to accept having a cesarean birth. Many of the women discussed the notion that it was easier to accept having a cesarean birth because they thought it would lead to a healthy baby. Other women relied on their faith and support from others. One participant explained, "I think 
having a supportive partner, my husband, and faith in God that this was meant to be for some reason; it helped me to accept having a cesarean delivery."

\section{Theme 3: Emotional Roller Coaster of Birth}

Childbirth by nature is a very emotional experience. One of the women described a strictly positive experience, "I felt calm going in for surgery." Two of the women expressed only negative emotions related to the birth, "I actually hyperventilated through the entire delivery of my children and panicked the entire time." Another woman explained that her husband was fearful as well,

I think he wasn't prepared for it [the surgery] either because he never held my hand. If I just had someone be able to hold my hand I think I would have felt better but I didn't even have that.

The remaining women described a range of emotions that often fluctuated between positive and negative. All of the women experienced some sense of fear either related to the surgery or the anesthesia. One participant explained,

I think once I knew I was getting a needle in my spine that was when it hit me. Oh my God I could be paralyzed. Oh my God well wait a minute I am paralyzed now I can't feel a dang thing.

Another woman expressed similar sentiments,

It was weird this time because you were awake and actually heard and smelled everything. Like the flesh burning so that was kind of freaky to be like what's that smell, oh wait that's my skin burning when they are cutting me open.

The fear of anesthesia was often compounded by the fact that the support person was not allowed in the operating room while the anesthesia was placed. The women needed to rely on the nursing staff for support. One woman explained, "To make it worse there is no one in the room with you except the nurses and the anesthesiologist, but they are strangers." Even those women who requested a cesarean birth expressed moments of self-doubt. One participant shared,

I was gung-ho ready to do the c-section until I got on the table to do the spinal. They struggled to get the spinal in. . I was about to change my mind and say forget this I can go home and wait it out.
Seven of the women discussed how negative emotions turned into positive feelings of joy and relief upon the birth of the baby. Upon seeing her baby for the first time one mother shared, "I still remember feeling like I was floating in the air. No pain. Pure joy and excitement!" Several women were able to do skin-to-skin in the operating room which further increased the positive emotions. One participant remembered, "They brought her to me and I held her on the table. That was one thing I told my husband I wanted and I was thrilled."

\section{Theme 4: Physical Recovery, Feeling Like Myself}

While a cesarean birth is a major abdominal surgery the extent of recovery varied significantly between the participants. Some participants reported feeling fully recovered in as little as 2 weeks, while others felt it took up to a year to return to normal. Whether or not the woman requested the cesarean birth did not impact the length of recovery. Eight of the participants described their recovery as easy. One woman shared, "I didn't feel like there was anything I couldn't do because of the cesarean." In contrast, three of the women described long painful recoveries. One woman explained,

Six weeks came and went and I was expecting to feel better and I didn't. I was still very weak and tired; I couldn't lift things. It took a full year before I felt like I had regained my body.

For three of the participants, their physical recovery was compounded by breastfeeding difficulties. One woman explained, “The baby just couldn't latch on, I couldn't hold her right, the incision was bothering me, and I just didn't know what I was doing."

All of the participants except one discussed the positive impact of support on their physical recovery. Participants described how family and friends would help with household chores, baby advice, and infant care. Six of the women also commented on the importance of exercise during pregnancy and being physically active after their surgery.

\section{Theme 5: Emotional Recovery, a Kaleidoscope of Feelings}

For most of the participants, the emotional recovery was much more difficult than the physical recovery with only three of the participants describing their emotional recovery as easy. Most of the woman

For most of the participants the emotional recovery was much more difficult than the physical recovery. 
discussed feelings of "depression" or "increased levels of anxiety." One woman explained, "Emotionally I was so tired when I came home. I felt like I was being a machine, just doing and doing .... It was a couple of weeks later when it hit me and I broke down." For some women, breastfeeding difficulties added to their emotional distress. One woman remembered, "I was trying to do it all but with very little information or help. So, I gave up at about eight weeks. . I didn't feel like I was being a very good mother."

Five of the participants discussed how the presence of support and social interaction positively impacted their emotional recovery. One participant explained, "I didn't have postpartum depression at all and I feel like perhaps part of that is due to the fact that I did have someone there with me all day long helping me with everything." Another participant explained, "It was summer so I was able to get out and go for walks and visit people. I wasn't cooped up anywhere. I felt like myself."

\section{Theme 6: Expectations, a Picture in my Mind}

Seven of the participants discussed their expectations in relation to their experience. Five of the women described their experience as having met or exceeded their expectations. One woman shared, "So we [the doctor and the participant] went through everything from soup to nuts. So, I felt very prepared for what was going to happen." Another woman explained how the staff positively impacted her, "I think the people make the experience and everyone I had that day did their best to make me comfortable."

Two of the women had birthing experiences worse than they expected. For these women, confident staff led to feelings of being ignored, "I think the doctors do this day in and day out and they kind of forget." She went on to explain, "what I was missing was the actual common ground that a woman would give you who had been through it before. . like someone to tell me to remain calm." Another participant explained how she felt unprepared because "I was in a fog and couldn't remember what the doctor had told me was going to happen."

\section{Theme 7: Outcomes, Ties That Bind}

Seven of the participants discussed the end result of their cesarean birth. Regardless of whether the participant wanted a cesarean birth or not, all of the women were happy with the outcome. One participant shared, "I am very happy with the choice I made and with the aftermath of it." Some women discussed changes in their relationships with friends, in-laws, and even spouses. One participant explained, "If you don't have support, you don't have parents, you don't have in-laws around then you have to rely on each other and it certainly made us stronger as a couple." Another woman explained changes in herself, "Having been through that [a cesarean birth] there's nothing in life I won't be able to conquer!"

\section{DISCUSSION}

Roy's Adaptation Model allowed for the analysis of first-time mothers' perceptions of responses to a planned cesarean birth. The emerging seven themes and metastory reflected more adaptive responses than ineffective in each of the four adaptive modes in RAM. Women's ability to accept an alternative birth method is very limited in the literature. Redshaw and Hockley (2010) conducted the only study that addressed adjusting to a cesarean birth. While all the women in this author's study had planned cesareans, several of the women requested this method, while others had wanted a vaginal birth, therefore, the stimuli were slightly different among the study participants. These results suggest the stimuli did not impact the adaptation as both groups of participants demonstrated adaptive responses. Instead, the narratives revealed the modes of adaptation were impacted by the cognator subsystems specifically perceptual processing, emotion, and judgment rather than the stimulus of a planned cesarean birth. These results support one of the model's generic propositions that states, "the adequacy of the cognator and regulator processes affects adaptive responses" (Roy \& Andrews, 1999, p. 547).

The results of this narrative analysis support findings from previous research that first-time mothers having a planned cesarean birth rarely did so because of maternal request (Kingdon et al., 2009; Robson, Tan, Adeyemi, \& Dear, 2009; Thompson, 2010). Similar to a previous report (Puia, 2013a), the two women in this study that did request a cesarean believed they had medical concerns that warranted a cesarean birth. As was supported by earlier studies (Declerq, Sakala, Corry, Applebaum, \& Herrlich, 2013; Fenwick, Staff, Gamble, Creedy, \& Bayes, 2010; Kingdon et al., 2009; Puia, 2013a), the remaining 
nine participants in this study, all desired a vaginal birth, but felt compelled to have a cesarean birth due to the risks to the baby and/or physician recommendation. All of the participants in this author's study described feeling as if they had no safe alternatives, but to have a cesarean birth. This illusion of choice in birth method is also addressed in the literature (Redshaw \& Hockley, 2010; Wittmann-Price, Fliszar, \& Bhattacharya, 2011).

The negative emotions of fear, anxiety, and depression are similar to previous reports (Blüml et al., 2012; Fries, 2010; Puia, 2013b; Redshaw \& Hockley, 2010; Wilde-Larsson, Sandin-Bojö, Starrin, \& Larsson, 2011). Physical recovery was gauged by the women not by the healing of the wound, but by how long it took to "feel like themselves." A majority of participants in this author's study described easy recoveries with minimal pain, no physical restrictions, and a quick return to normal living. The literature rarely explored these quick recoveries, but rather more commonly addressed the difficulties with mobility and caring for an infant (Kealy, Small, \& Liamputtong, 2010; Puia, 2013b). Difficulties with infant care, in particular breastfeeding, was also seen in this author's study. The negative impact of cesarean births on breastfeeding also emerged in similar studies (Augustin, Donovan, Lozano, Massucci, \& Wohlgemuth, 2014; Chalmers et al., 2010; Zanardo et al., 2010).

Preconceived ideas about how childbirth will unfold may influence one's level of satisfaction. The literature validates the results of this study which reveal satisfying experiences were not restricted to only those women who wanted a cesarean birth (Blomquist, Quiroz, Macmillan, McCullough, \& Handa, 2011; Blüml et al., 2012). The influence of negative expectations, provider behavior, and adequacy of information on women's experiences and levels of satisfaction was also supported (Bryanton et al., 2008; Kolip \& Büchter, 2009; Puia, 2013a; Redshaw \& Hockley, 2010). Several participants in this author's study also discussed how their partners were unprepared for the realities of a cesarean birth, leading to an increased amount of fear. The need for the partner to be prepared and able to provide support emerged is a similar study (Bryanton et al., 2008).

The positive experiences were partially attributed to maternal infant contact, such as skin-to-skin in the operating room, and are similar to a previous report (Bryanton et al., 2008). Seven participants in this author's study discussed the outcomes of their cesarean birth, all of which were happy with the aftermath. Whether or not the woman wanted a cesarean birth did not impact the end result as women who had wanted a vaginal birth also reported positive outcomes. The literature supports these findings (Blomquist et al., 2011; Kolip \& Büchter, 2009; Puia, 2013a; Robson, Tan, Adeyemi, \& Dear, 2009).

This author's study has many strengths. The subjective nature of childbirth and its importance in establishing maternal identity made narrative analysis a fitting method to capture first-time mothers' experiences of a planned cesarean birth. The recruitment strategy resulted in a sample representing four different states. This is significant since cesarean birth rates and practices differ between states. However, all of the states represented were from the Eastern Coast of the United States and thus a sample more illustrative of the diverse geographical regions of the country may deliver a more accurate portrayal. In addition, ethnic and socioeconomic differences were not represented as all of the participants were white, married, and welleducated women. The homogeneity of the sample is a limitation of this study. Another limitation of the study is that while the women were all firsttime mothers at the time of the cesarean, some of the participants had since had other children by the time of the interview. Having had other birthing experiences may have impacted how the women interpreted their first birth.

Another strength of this study was the data collection methods. Some of the participants crafted their story and sent it via email to the researcher. Other participants chose to be interviewed face-toface. The use of both Internet and in person interviews allowed for the triangulation of data, which provides a more truthful depiction of reality (Polit \& Beck, 2012).

Riessman (1993) supports the use of the term "trustworthiness" in narrative research instead of validity. Trustworthiness was evaluated on the criteria of credibility, confirmability, and transferability. Credibility was enhanced by the following steps: a detailed description of the data collection and analysis methods was included; the use of data collection triangulation via both interviews and written narratives; and verbatim transcription of data. The use of the participants' exact words to 
provide thick description of the themes increase the transferability. Confirmability was achieved when the narratives and the resulting themes were returned to the participants for validation and all participants concurred that the results reflected their experience of a planned cesarean birth as a first-time mother.

\section{CLINICAL IMPLICATIONS}

This research has many implications for practice, education, and research. Implications for nursing practice should begin with an assessment of the woman's birth plan. Nurses must advocate for the incorporation of the woman's desires into a cesarean birth. For example, providing skin-to-skin while still in the operating room. Nursing needs to work to improve institutional policies to decrease maternal infant separation during a cesarean birth. In addition to their birth plan, evaluation of a woman's emotions related to a cesarean birth should occur. Women's feelings should be assessed both prenatally and postpartum as feelings about cesarean birth may change. Finally, the knowledge level of the woman and her support person about cesarean births should be determined. Nurses need to address any fears or concerns and accurate information should be offered along with ample opportunities for questions. Nurses also need to provide continuous emotional support, especially, during the procedure to help alleviate patients' feelings of being ignored. Patient education should be repeatedly presented in order to ensure comprehension. Education sessions need to incorporate the support person, since increased partner fear can lead to decreased satisfaction for the woman. Breastfeeding issues can lead to increased difficulties with physical and emotional recovery. Therefore, nurses need to provide additional breastfeeding education specific to those women who had a cesarean birth. Increased follow-up with breastfeeding mothers should occur in the hospital and after discharge.

In addition to patient education, health-care providers should be educated to address emotions related to having an unwanted planned cesarean birth. For many women, despite having a positive outcome, they may struggle with not having a vaginal birth. Opportunities must be made to assess the women's level of adaptation and when needed, provide additional support. It is important to recognize that just because a cesarean is planned does not mean the birth will automatically be a satisfying experience for the women. The behaviors of health-care providers, as evidenced by the results of this study, strongly influence the women's experiences. Participants expected not only knowledge and expertize, but also caring and compassionate actions like holding a hand or brief conversations to provide distraction and reduce fears.

In order to continue to improve the care of firsttime mothers having a planned cesarean birth, further research is needed. First, additional studies should be conducted with women from varied socioeconomic, ethnic, and geographic backgrounds to determine if needs vary. Other studies need to address the timing and specific educational needs of first-time mothers having a planned cesarean birth. The educational needs as well as the thoughts and emotions of the support person should be evaluated as well. Further studies should explore the impact of peer mentor support groups for first-time mothers having a planned cesarean birth.

\section{CONCLUSION}

The unique physical, emotional, and educational needs of first-time mothers having a planned cesarean birth need to be recognized by clinicians. The results of this study deliver a unique insight and increase health-care providers' understanding of the primipara's experience. Specialized interventions specific to this population need to be added to cesarean birth best practices. Improved care will ultimately lead to more positive experiences for first-time mothers having a planned cesarean birth.

\section{REFERENCES}

Augustin, A. L., Donovan, K., Lozano, E. A., Massucci, D. J., \& Wohlgemuth, F. (2014). Still nursing at 6 months: A survey of breastfeeding mothers. The American Journal of Maternal Child Nursing, 39(1), 50-55. http://dx.doi. org/10.1097/01.NMC.0000437534.99514.dc

Blomquist, J.L., Quiroz, L. H., MacMillan, D., McCullough, A., \& Handa, V. L. (2011). Mothers' satisfaction with planned vaginal and planned cesarean birth. American Journal of Perinatology, 28(5), 383-388. http://dx.doi. org/10.1055/s-0031-1274508

Blüml, V., Stammler-Safar, M., Reitinger, A. K., Resch, I., Naderer, A., \& Leithner, K. (2012). A qualitative approach to examine women's experience of planned cesarean. Journal of Obstetric, Gynecologic \& Neonatal Nursing, 41(6), E82-E90. http://dx.doi.org/10.1111/j. 1552-6909.2012.01398.x 
Bryanton, J., Gagnon, A. J., Johnston, C., \& Hatem, M. (2008). Predictors of women's perceptions of the childbirth experience. Journal of Obstetric, Gynecologic \& Neonatal Nursing, 37(1), 24-34. http://dx.doi.org/ 10.1111/j.1552-6909.2007.00203.x

Chalmers, B., Kaczorowski, J., Darling, E., Heaman, M., Fell, D. B., O’Brien, B., Lee, L., \& for the Maternity Experiences Study Group of the Canadian Perinatal Surveillance System. (2010). Cesarean and vaginal birth in Canadian women: A comparison of experiences. Birth, 37(1), 44-49. http://dx.doi.org/10.1111/j. 1523-536X.2009.00377.x

Dahlen, H. G., Barclay, L. M., \& Homer, C. S. E. (2010). The novice birthing: Theorizing first-time mothers' experiences of birth at home and in hospital in Australia. Midwifery, 26(1), 53-63. http://dx.doi.org/ 10.1016/j.midw.2008.01.012

Declerq, E. R., Sakala, C., Corry, M. P., Applebaum, S., \& Herrlich, A. (2013). Listening to Mothers III: Pregnancy and childbirth. Retrieved from http://transform.childbirthconnection.org/wp-content/uploads/2013/06/ LTM-III_Pregnancy-and-Birth.pdf

Fenwick, J., Staff, L., Gamble, J., Creedy, D. K., \& Bayes, S. (2010). Why do women request caesarean section in a normal. healthy First Pregnancy? Midwifery, 26, 394-400.

Fries, K. S. (2010). African American women and unplanned cesarean birth. American Journal of Maternal Child Nursing, 35(2), 110-115. http://dx.doi. org/10.1097/NMC.0b013e3181caebd7

Guise, J. -M., Denman, M. A., Emeis, C., Marshall, N., Walker, M., Fu, R., McDonagh, M. . . . (2010). Vaginal birth after cesarean. Obstetrics \& Gynecology, 115(6), 1267-1278. http://dx.doi.org/10.1097/AOG. 0b013e3181df925f

Hamilton, B. E., Martin, J. A., Osterman, M. J. K., Curtin, S. C., \& Mathews, T. J. (2015). Births: Final Data for 2014. National Vital Statistics Report, 641 (12)-64.

Karlström, A., Nystedt, A., \& Hildingsson, I. (2011). A comparative study of the experience of childbirth between women who preferred and had a caesarean section and women who preferred and had a vaginal birth. Sexual \& Reproductive Healthcare, 2(3), 93-99. http://dx.doi.org/10.1016/j.srhc.2011.03.002

Kealy, M. A., Small, R. E., \& Liamputtong, P. (2010). Recovery after caesarean birth: A qualitative study of women's accounts in Victoria, Australia. BMC Pregnancy and Childbirth, 10(1), 47-58. http://dx.doi. org/10.1186/1471-2393-10-47

Kingdon, C., Neilson, J., Singleton, V., Gyte, G., Hart, A., Gabbay, M., \& Lavender, T. (2009). Choice and birth method: Mixed-method study of caesarean delivery for maternal request. BJOG: An International Journal of Obstetrics \& Gynaecology, 116(7), 886-895. http:// dx.doi.org/10.1111/j.1471-0528.2009.02119.x

Kolip, P., \& Büchter, R. (2009). Involvement of first-time mothers with different levels of education in the decision-making for their delivery by a planned Caesarean section. Women's satisfaction with information given by gynaecologists and midwives. Journal of Public
Health, 17(4), 273-280. http://dx.doi.org/10.1007/ s10389-008-0246-1

Polit, D. F., \& Beck, C. T. (2012). Nursing research generating and assessing evidence for nursing practice (9th ed.). Philadelphia, PA: Wolters.

Puia, D. M. (2013a). The cesarean decision survey. The Journal of Perinatal Education, 22(4), 212-225. http:// dx.doi.org/10.1891/1058-1243.22.4.212

Puia, D. (2013b). A meta-synthesis of women's experiences of cesarean birth. MCN American Journal of Maternal Child Nursing, 38(1), 41-47. http://dx.doi. org/10.1097/NMC.0b013e31826aa855

Redshaw, M., \& Hockley, C. (2010). Institutional processes and individual responses: Women's experiences of care in relation to cesarean birth. Birth, 37(2), 150-159. http://dx.doi.org/10.1111/j.1523-536X.2010.00395.x

Riessman, C. K. (1993). Narrative analysis. Newbury Park, CA: Sage.

Riessman, C. K. (2008). Narrative methods for the human sciences. Thousand Oaks, CA: Sage.

Robson, S. J., Tan, W. S., Adeyemi, A., \& Dear, K. B. G. (2009). Estimating the rate of cesarean section by maternal request: Anonymous survey of obstetricians in Australia. Birth, 36(3), 208-212. http://dx.doi.org/ 10.1111/j.1523-536X.2009.00331.x

Roy, S. C., \& Andrews, H. A. (1999). The Roy adaptation model. Chestnut Hill, CT: Appleton \& Lange.

Simkin, P. (1992). Just another day in a woman's life? Part 11: Nature and consistency of women's long-term memories of their first birth experiences. Birth, 19(2), 64-81. http://dx.doi.org/10.1111/j.1523-536X.1992. tb00382.x

Stadlmayr, W., Amsler, F., Lemola, S., Stein, S., Alt, M., Bürgin, D., Bitzer, J. . . . (2006). Memory of childbirth in the second year: The long-term effect of a negative birth experience and its modulation by the perceived intranatal relationship with caregivers. Journal of Psychosomatic Obstetrics \& Gynecology, 27(4), 211224. http://dx.doi.org/10.1080/01674820600804276

Thompson, H. (2010). Caesarean section at maternal request: A literature review. British Journal of Midwifery, 18(8), 484-491Retrieved from. http://dx. doi.org/10.12968/bjom.2010.18.8.49315

Waldenstrom, U. (2003). Women's Memory of childbirth at two months and one year after the birth. Birth, 30(4), 248-254. http://dx.doi.org/10.1046/j.1523-536X $.2003 .00254 . \mathrm{x}$

Weiss, A. J., Elixhauser, A., \& Andrews, R. M. (2014). Characteristics of operating room procedures in U.S. hospitals, 2011. (HCUP Statistical Brief \#170). Rockville, MD: Agency for Healthcare Research and Quality.

Wilde-Larsson, B., Sandin-Bojö, A. -K., Starrin, B., \& Larsson, G. (2011). Birthgiving women's feelings and perceptions of quality of intrapartal care: A nationwide Swedish cross-sectional study. Journal of Clinical Nursing, 20(7-8), 1168-1177. http://dx.doi.org/10. 1111/j.1365-2702.2010.03393.x

Wittmann-Price, R. A., Fliszar, R., \& Bhattacharya, A. (2011). Elective cesarean births: Are women making emancipated decisions? Applied Nursing Research, 24(3), 147-152. http://dx.doi.org/10.1016/j.apnr.2009.08.002 
Zanardo, V., Svegliado, G., Cavallin, F., Giustardi, A., Cosmi, E., Litta, P., \& Trevisanuto, D. (2010). Elective cesarean delivery: Does it have a negative effect on breastfeeding? Birth, 37(4), 275-279. http://dx.doi.org/ 10.1111/j.1523-536X.2010.00421.x

Zhang, J., Troendle, J., Reddy, U. M., Laughon, S. K., Branch, D. W., Burkman, R., . . Consortium on Safe Labor. (2010). Contemporary cesarean delivery practice in the United States. American Journal of Obstetrics and Gynecology, 203(4), 326.e1-32326. http://dx.doi. org/10.1016/j.ajog.2010.06.058

DENISE PUIA has been an assistant professor at the University of Saint Joseph for the past four years and presented at numerous regional conferences on issues related to childbirth. She has 25 years of experience as a labor and delivery nurse. 